\title{
MicroRNA-140-5p is Downregulated in Osteosarcoma and Overexpression of MicroRNA-140-5p Inhibits Cancer Cell Proliferation by Downregulating GLUT-I
}

This article was published in the following Dove Press journal: OncoTargets and Therapy

\section{Xiaoling Geng' \\ Haoyu Wang ${ }^{2}$ \\ Lichen $\mathrm{Xu}^{3}$ \\ Yazhou $\mathrm{Han}^{3}$ \\ Yadong $\mathrm{Liu}^{3}$}

'Department of Gastroenterology \& Hepatology, First Affiliated Hospital of Dalian Medical University, Dalian, I I6000, People's Republic of China; ${ }^{2}$ Department of Orthopedics, The Second Affiliated Hospital, Xi'an Jiaotong University, Xi'an, 7I0004, Shanxi, People's Republic of China; ${ }^{3}$ Department of Orthopedics, Dalian Municipal Central Hospital Affiliated of Dalian Medical University, Dalian, II6000, People's Republic of China
Correspondence: Yadong Liu

Dalian Municipal Central Hospital Affiliated of Dalian Medical University, Xuegong Street No. 42, Dalian, II6000, People's Republic of China

Email doctoryadong@163.com
Background: MicroRNA-140-5p plays pivotal role in different types of human malignancies, while its involvement in osteosarcoma is unknown.

Objective: Our study aimed to investigate the functionality of microRNA-140-5p in osteosarcoma.

Methods: Plasma levels of microRNA-140-5p and glucose transporter 1 (GLUT-1) in both osteosarcoma and healthy controls were measured by qRT-PCR and ELISA, respectively. Correlation between plasma levels of microRNA-140-5p and GLUT-1 was analyzed by Pearson correlation coefficient. Correlation between plasma levels of microRNA-140-5p and clinical data of patients with osteosarcoma was analyzed by Chi-square test. MicroRNA-140-5p mimic and GLUT-1 expression vector were transfected into cells of human osteosarcoma cell lines, and the effects on microRNA-140-5p expression, GLUT-1 expression and cell proliferation were analyzed by qRT-PCR, Western-blot and CCK-8 assay, respectively.

Results: Plasma levels of microRNA-140-5p were significantly lower and plasma levels of GLUT-1 were significantly higher in osteosarcoma patients than that in healthy controls. Levels of plasma microRNA-140-5p and GLUT-1 were reversely correlated in osteosarcoma patients. Plasma levels of microRNA-140-5p were correlated with tumor size but not with other clinical data of patients. MicroRNA-140-5p mimic significantly inhibited cancer cell proliferation, while GLUT-1 overexpression significantly promoted cancer cell proliferation. MicroRNA-140-5p mimic significantly downregulated GLUT-1 expression.

Conclusion: GLUT-1 overexpression showed no significant effect on microRNA-140-5p expression but attenuated the inhibitory effects of microRNA-140-5p mimic on cell proliferation. We therefore conclude that microRNA-140-5p is downregulated in osteosarcoma and overexpression of microRNA-140-5p may inhibit cancer cell proliferation by downregulating GLUT-1.

Keywords: osteosarcoma, microRNA-140-5p, glucose transporter 1, proliferation

\section{Introduction}

As a type of malignant tumor that develops from bone, osteosarcoma mainly affects children and adolescents. ${ }^{1}$ About $75 \%$ of the patients are $15-25$ years old, and most are male. The prognosis of osteosarcoma patients is very poor, although many novel anti-cancer drugs or molecular targeted therapies have been developed over last few decades, the 5-year survival rate of patients with osteosarcoma is still around 
$60 \%{ }^{2,3}$ In spite of the efforts been made on the treatment of osteosarcoma, outcomes are still unsatisfactory, ${ }^{4-6}$ leading to poor survival among those patients. Tumor growth provides the basis of almost all aspects of tumor biology and inhibition of tumor growth is considered to be promising target for the treatment of osteosarcoma. ${ }^{7}$

Compared with normal cells, cancer cells show abnormally accelerated energy metabolism. ${ }^{8}$ How to inhibit energy metabolism in cancer cells is a major task in the treatment of cancers. ${ }^{9}$ Glucose transporter 1, or GLUT-1, is a uniporter protein that mediates the transport of glucose across mammalian cell plasma membrane. ${ }^{10}$ With this ability, GLUT-1 plays a central role in glucose metabolism. ${ }^{11}$ It has been reported that expression of GLUT-1 is mediated by certain microRNAs, ${ }^{12}$ which also plays critical roles in cancer biology. ${ }^{13}$ MicroRNA-140-5p is reported to play an oncogenic role in several types of malignancies, ${ }^{14,15}$ while its expression pattern and functionality in osteosarcoma is unknown. In the present study we found that microRNA$140-5 p$ is downregulated in osteosarcoma and overexpression of microRNA-140-5p may inhibit cancer cell proliferation by downregulating GLUT-1.

\section{Patients and Methods}

\section{Patients and Plasma}

Our study enrolled 42 patients with osteosarcoma from January 2016 to January 2018 in the Hospital. Inclusion criteria are: 1) osteosarcoma patients diagnosed by pathological examinations; 2) patients willing to participate and fully understood the experimental protocol. Exclusion criteria: 1) patients complicated by other severe diseases; 2) patients with chronic diseases; 3 ) patients received treatment within 3 months before admission. There were 25 males and 17 females, with an age range of 19 to 48 years and a mean age of $33.2 \pm 5.4$ years. At the same time, our study also included 38 healthy volunteers to serve as control group. Control group included 23 males and 15 females, with an age range of 18 to 45 years and a mean age of $32.1 \pm 4.9$ years. Blood was extracted from each participant before breakfast one day after the admission. Plasma was prepared using the conventional method. Tumor tissues and adjacent tissues within $2 \mathrm{~cm}$ around tumors were collected from 18 patients with primary osteosarcoma who underwent surgery. Tissues were confirmed by pathological examinations. Tissues were snap frozen in liquid nitrogen and stored at $-80^{\circ} \mathrm{C}$, and used for subsequent RNA extraction. Our study was approved by the ethics committee of Dalian Municipal
Central Hospital Affiliated of Dalian Medical University, and was conducted in accordance with the Declaration of Helsinki. All participants fully understood the whole experimental protocol and signed informed consent. Following neoadjuvant chemotherapy, the patients underwent wide resection of tumors. Response to chemotherapy was classified as "poor" ( $<90 \%$ tumor necrosis) and "good" ( $>90 \%$ tumor necrosis) through histologic analysis of tumor specimens after surgery. The characteristics of these patients are shown in Table 1. Frequent smoking was defined as $>10$ cigarettes per day, $>4$ days per week. Rare smoking was defined as $\leq 10$ cigarettes per day and/or $\leq 4$ days per week. Frequent drinking was defined as $>3$ times per week. Rare smoking was defined $\leq 3$ times per week. $p<0.05$ indicated a statistically significant difference.

\section{RNA Insolation and Quantitative Real-Time Polymerase Chain Reaction (qRT-PCR)}

Following total RNA extraction using TRIzol reagent (Thermo Fisher Scientific), miRNA was extracted using TaqMan miRNA Isolation kit (Applied Biosystems, Foster City, CA, USA). After reverse transcription, qRT-PCR was performed to measure the expression level of microRNA140-5p and GLUT-1 with U6 small nuclear RNA (snRNA) and $\beta$-actin as the endogenous controls, respectively. All PCR reactions were performed on StepOnePlus real-time PCR system (Applied Biosystems, Foster City, CA, USA). Thermal reaction conditions of PCR reactions were: $1 \mathrm{~min}$ at $95^{\circ} \mathrm{C}$, followed by 40 cycles of $10 \mathrm{~s}$ at $95^{\circ} \mathrm{C}$ and $25 \mathrm{~s}$ at $59.5^{\circ} \mathrm{C}$. This experiment was performed in triplicate manner and $2^{-\Delta \Delta \mathrm{CT}}$ method was used for data normalization.

\section{Enzyme-Linked Immunosorbent Assay (ELISA)}

Plasma levels of GLUT-1 were measured by ELISA using human glucose transporter 1 ELISA kit (MyBioSource). All operations were performed in strict accordance with instructions of the kit. Plasma levels of GLUT-1 were normalized to $\mathrm{ng} / \mathrm{mL}$.

\section{Cell Culture and Transfection}

MG-63 and U2OS human osteosarcoma cell lines were purchased from ATCC (USA). Eagle's Minimum Essential Medium (Cat No. 30-2003, ATCC, USA) supplemented with $10 \%$ heat-inactivated fetal bovine serum was used to culture cells at $37^{\circ} \mathrm{C}$ in a $5 \% \mathrm{CO}_{2}$ incubator. MISSION ${ }^{\circledR}$ 
Table I Correlation Between Plasma Levels of MicroRNA-140-5p and Clinical Data of Patients with Osteosarcoma

\begin{tabular}{|c|c|c|c|c|c|c|}
\hline Variables & Groups & Cases & High-Expression & Low-Expression & $X^{2}$ & p value \\
\hline Gender & $\begin{array}{l}\text { Male } \\
\text { Female }\end{array}$ & $\begin{array}{l}25 \\
17\end{array}$ & $\begin{array}{l}11 \\
10\end{array}$ & $\begin{array}{l}14 \\
7\end{array}$ & 0.89 & 0.35 \\
\hline Age & $\begin{array}{l}>30 \text { (years) } \\
<30 \text { (years) }\end{array}$ & $\begin{array}{l}24 \\
18\end{array}$ & $\begin{array}{l}11 \\
10\end{array}$ & $\begin{array}{l}13 \\
8\end{array}$ & 0.38 & 0.53 \\
\hline BMI & $\begin{array}{l}>23.9 \\
18.4-23.9 \\
<18.4\end{array}$ & $\begin{array}{l}12 \\
21 \\
9\end{array}$ & $\begin{array}{l}7 \\
9 \\
5\end{array}$ & $\begin{array}{l}5 \\
11 \\
4\end{array}$ & 0.62 & 0.73 \\
\hline Tumor size & $\begin{array}{l}>5 \mathrm{~cm} \\
2-5 \mathrm{~cm} \\
<2 \mathrm{~cm}\end{array}$ & $\begin{array}{l}14 \\
18 \\
10\end{array}$ & $\begin{array}{l}3 \\
10 \\
8\end{array}$ & $\begin{array}{l}11 \\
8 \\
2\end{array}$ & 8.39 & 0.02 \\
\hline Tumor grade & $\begin{array}{l}\text { Low } \\
\text { High }\end{array}$ & $\begin{array}{l}20 \\
8\end{array}$ & $\begin{array}{l}12 \\
6\end{array}$ & $\begin{array}{l}10 \\
2\end{array}$ & 2.04 & 0.15 \\
\hline \multicolumn{7}{|c|}{ Response to pre-operative chemotherapy } \\
\hline & $\begin{array}{l}\text { Good } \\
\text { Poor }\end{array}$ & $\begin{array}{l}14 \\
14\end{array}$ & $\begin{array}{l}9 \\
8\end{array}$ & $\begin{array}{l}5 \\
6\end{array}$ & 0.04 & 0.83 \\
\hline \multicolumn{7}{|l|}{ Survival (months) } \\
\hline & $\begin{array}{l}0-40 \\
40-80 \\
>80\end{array}$ & $\begin{array}{l}1 \\
5 \\
12\end{array}$ & $\begin{array}{l}0 \\
3 \\
7\end{array}$ & $\begin{array}{l}1 \\
2 \\
5\end{array}$ & 0.01 & 0.92 \\
\hline Distant metastasis & $\begin{array}{l}\text { Yes } \\
\text { No }\end{array}$ & $\begin{array}{l}20 \\
22\end{array}$ & $\begin{array}{l}8 \\
13\end{array}$ & $\begin{array}{l}12 \\
9\end{array}$ & 1.53 & 0.22 \\
\hline Smoking & $\begin{array}{l}\text { Frequent } \\
\text { Rare } \\
\text { No }\end{array}$ & $\begin{array}{l}18 \\
9 \\
15\end{array}$ & $\begin{array}{l}8 \\
6 \\
7\end{array}$ & $\begin{array}{l}10 \\
3 \\
8\end{array}$ & 1.29 & 0.52 \\
\hline Drinking & $\begin{array}{l}\text { Frequent } \\
\text { Rare } \\
\text { No }\end{array}$ & $\begin{array}{l}22 \\
10 \\
10\end{array}$ & $\begin{array}{l}12 \\
5 \\
4\end{array}$ & $\begin{array}{l}10 \\
5 \\
6\end{array}$ & 0.58 & 0.75 \\
\hline
\end{tabular}

microRNA Mimic hsa-miR-140-5p and MISSION ${ }^{\circledR}$ miRNA Negative Control 1 were bought from Sigma-Aldrich. Vectors express GLUT-1 and the empty vectors were provided by GeneCopoeia (Guangzhou, China). Lipofectamine ${ }^{\circledR} 2000$ Reagent (Thermo Fisher Scientific) was used to transfect 20 $\mathrm{nM}$ siRNA or $10 \mathrm{nM}$ vectors into $5 \times 10^{5}$ cells. Cells treated with Lipofectamine ${ }^{\circledR} 2000$ Reagent only were used as control cells. Overexpression rates of microRNA-140-5p and GLUT1 (generally $200 \%$ and $260 \%$ ) were confirmed by qRT-PCR before subsequent experiments.

\section{Cell Proliferation Assay}

After transfection, cells were harvested and cell suspensions with a cell density of $4 \times 10^{4}$ cells per well were prepared. $100 \mu \mathrm{L}$ cell suspension was added into each well of a 96 -well plate. Cells were cultured at $37^{\circ} \mathrm{C}$ in a $5 \% \mathrm{CO}_{2}$ incubator, followed by adding $10 \mu \mathrm{L}$ of CCK-8 solution 24, 48, 72 and $96 \mathrm{~h}$ later. After that, cells were cultured for additional $4 \mathrm{~h}$ and OD at $450 \mathrm{~nm}$ was measured. This experiment was performed in triplicate manner.

\section{Western-Blot}

Following total protein extraction using RIPA solutions (Thermo Fisher Scientific, USA), protein concentration was determined by BCA assay. Protein samples were denatured and subjected to $12 \%$ SDS-PAGE gel electrophoresis. After gel transfer to PVDF membranes, membranes were blocked in 
$5 \%$ skimmed milk for $1 \mathrm{~h}$ at room temperature. Rabbit antihuman primary antibodies including GLUT-1 (1:1200, ab15309, Abcam) and GAPDH (1:1300, ab8245, Abcam) were then used to culture membranes overnight at $4^{\circ} \mathrm{C}$. The next day, membranes were further incubated with goat antirabbit IgG-HRP (sc-2004, Santa Cruz Biotechnology). Signal were developed using ECL (Sigma-Aldrich, USA). MYECL ${ }^{\text {TM }}$ Imager (Thermo Fisher Scientific, USA) was used to detect signals and signals were normalized using Image J software. This experiment was performed in triplicate manner.

\section{Statistical Analysis}

All statistical analyses were performed using SPSS19.0 software (SPSS Inc., USA). All data were expressed as mean \pm standard. Comparisons between two groups were performed by Student's $t$-test. Comparisons among 3 groups were carried out one way analysis of variance, followed by Tukey's test. Correlation between plasma levels of microRNA-140$5 \mathrm{p}$ and GLUT-1 was analyzed by Pearson correlation coefficient. Correlation between plasma levels of microRNA-140-
$5 \mathrm{p}$ and clinical data of patients with osteosarcoma was analyzed by Chi-square test.

\section{Results}

Plasma Levels of MicroRNA-140-5p Were Significantly Lower, While Plasma Levels of GLUT-I Were Significantly Higher in Osteosarcoma Patients Than in Healthy Controls

We first measured plasma levels of microRNA-140-5p and GLUT-1 in both osteosarcoma and healthy controls by qRTPCR and ELISA, respectively. As shown in Figure 1, compared with healthy controls, significantly downregulated microRNA-140-5p (Figure 1A) and significantly upregulated GLUT-1 (Figure 1B) were found in patients with osteosarcoma. In addition, levels of microRNA-140-5p were significantly lower (Figure 1C) and levels of GLUT-1 mRNA (Figure 1D) were significantly higher in tumor tissues than in adjacent healthy tissues of osteosarcoma patients $(\mathrm{p}<0.05)$.
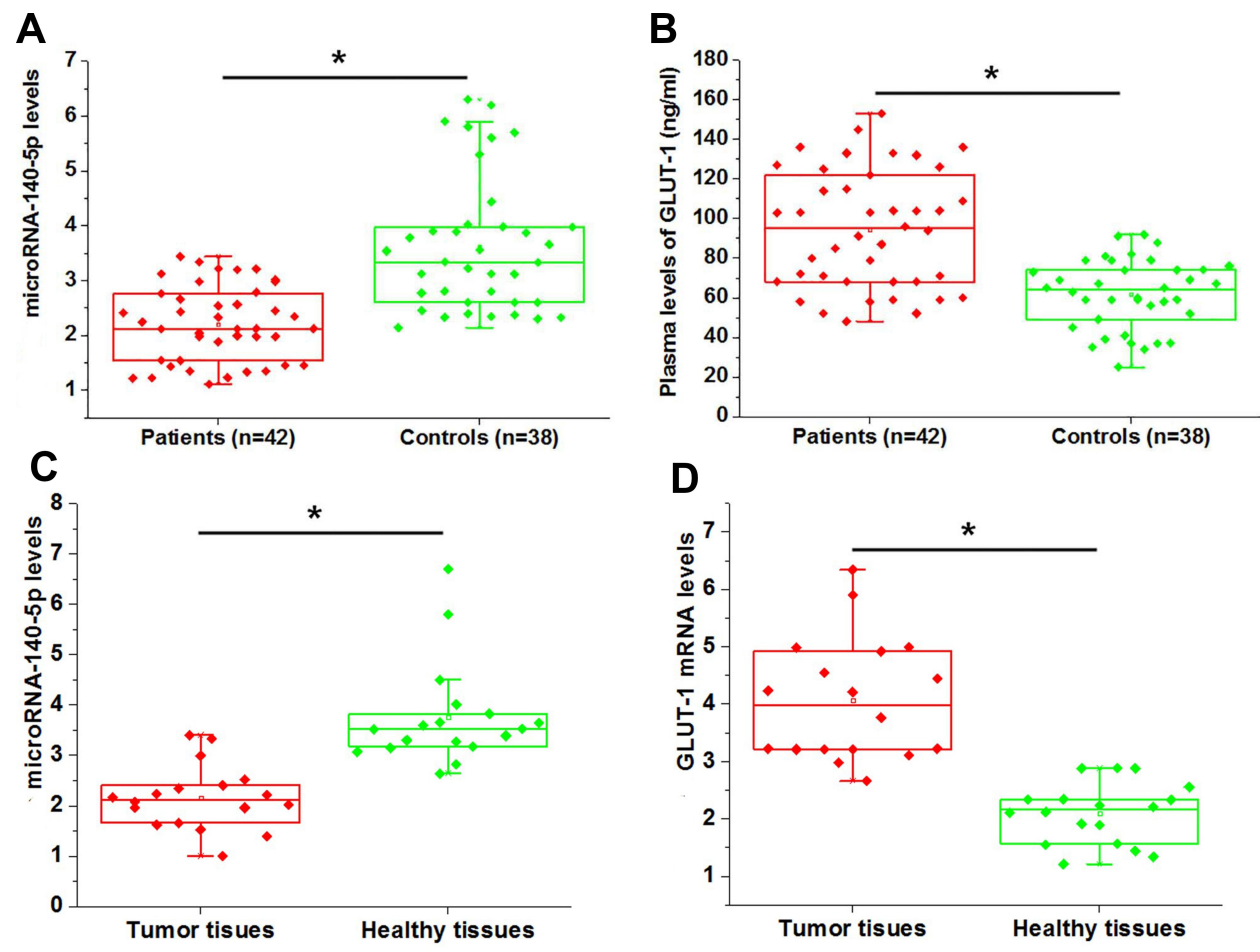

Figure I Plasma levels of microRNA-140-5p were significantly lower (A), while plasma levels of GLUT-I were significantly higher (B) in osteosarcoma patients than in healthy controls. In addition, levels of microRNA-140-5p were significantly lower (C) and levels of GLUT-I mRNA (D) were significantly higher in tumor tissues than in adjacent healthy tissues of osteosarcoma patients $\left({ }^{*} \mathrm{p}<0.05\right)$. 


\section{Plasma Levels of MicroRNA-I40-5p and GLUT-I Were Reversely Correlated in Osteosarcoma Patients but Not in Healthy Controls}

Correlation between plasma levels of microRNA-140-5p and GLUT-1 was analyzed by Pearson correlation coefficient. The results showed a significant reverse correlation between plasma levels of microRNA-140-5p and GLUT-1 in osteosarcoma patients (Figure 2A) but not in healthy controls (Figure 2B).

\section{Plasma Levels of MicroRNA-I40-5p Were Correlated with Tumor Size}

Correlation between plasma levels of microRNA-140-5p and clinical data of patients with osteosarcoma was analyzed by Chi-square test. As shown in Table 1, plasma levels of microRNA-140-5p showed no significant correlation with patients' age, gender, BMI, smoking and drinking habits. In contrast, a significant correlation between plasma levels of microRNA-140-5p and tumor size was observed.

\section{MicroRNA- I 40-5p Overexpression Led to Significantly Downregulated GLUT-I}

The negative correlation between microRNA-140-5p and GLUT-1 in osteosarcoma indicated the possible interaction between microRNA-140-5p and GLUT-1. To further explore the interactions between microRNA-140-5p and GLUT-1, microRNA-140-5p mimic and GLUT-1 expression vectors were transfected into cells of human osteosarcoma cell lines, following by detecting the expression of microRNA-140-5p mimic and GLUT-1. As shown in Figure 3A, compared with control (C) and negative control (NC), microRNA-140-5p mimic transfection led to significantly downregulated expression of GLUT-1 in cells of both MG-63 and U2OS cell lines (Figure 3A, $\mathrm{p}<0.05$ ). In contrast, GLUT-1 expression vector transfection did not significantly affect microRNA-140-5p expression (Figure 3B, $\mathrm{p}<0.05$ ).

\section{MicroRNA-140-5p Overexpression Inhibited Osteosarcoma Cell Proliferation by Downregulating GLUT-I}

The significant correlation between plasma levels of microRNA-140-5p and tumor size revealed the possible involvement of microRNA-140-5p in tumor growth. To further verify it, cell proliferation rate after microRNA-140-5p mimic transfection was measured by CCK- 8 assay. As shown in Figure 4, microRNA-140-5p mimic transfection, significantly reduced, while GLUT-1 vector transfection significantly promoted proliferation of cells of MG-63 and U2OS cell lines $(\mathrm{p}<0.05)$. In addition, GLUT-1 vector transfection significantly attenuated the inhibitory effects of microRNA$140-5 p$ mimic transfection on cell proliferation $(p<0.05)$.

\section{Discussion}

MicroRNA-140-5p is a characterized tumor suppression miRNA in several types of malignancies. The key finding of our study is that microRNA-140-5p may participate in the regulation of the growth of osteosarcoma through the interactions with GLUT-1. Our findings are based on the experimental data of human materials, which suggest the potential application value of microRNA-140-5p in clinical treatment of osteosarcoma.

The pathogenesis and progression of osteosarcoma is closely correlated to the altered expression of a large set of miRNAs. ${ }^{16}$ It has been reported that microRNA-199a-3p is downregulation in osteosarcoma, and the downregulation of microRNA-199a-3p causes promoted migration and invasion of cancer cells. ${ }^{17}$ In contrast, upregulation of

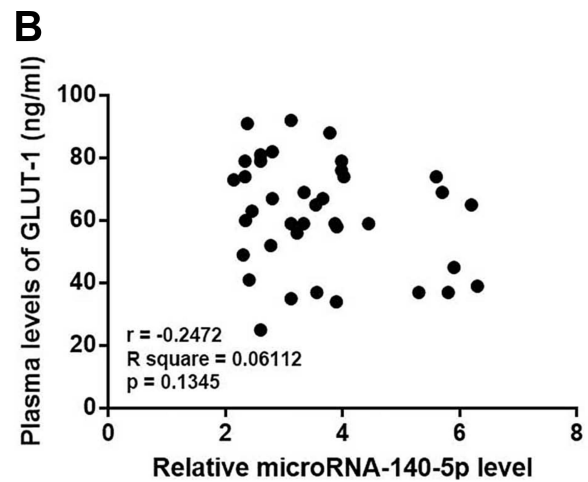

Figure 2 Plasma levels of microRNA-140-5p and GLUT-I were reversely correlated in osteosarcoma patients (A) but not in healthy controls (B). 

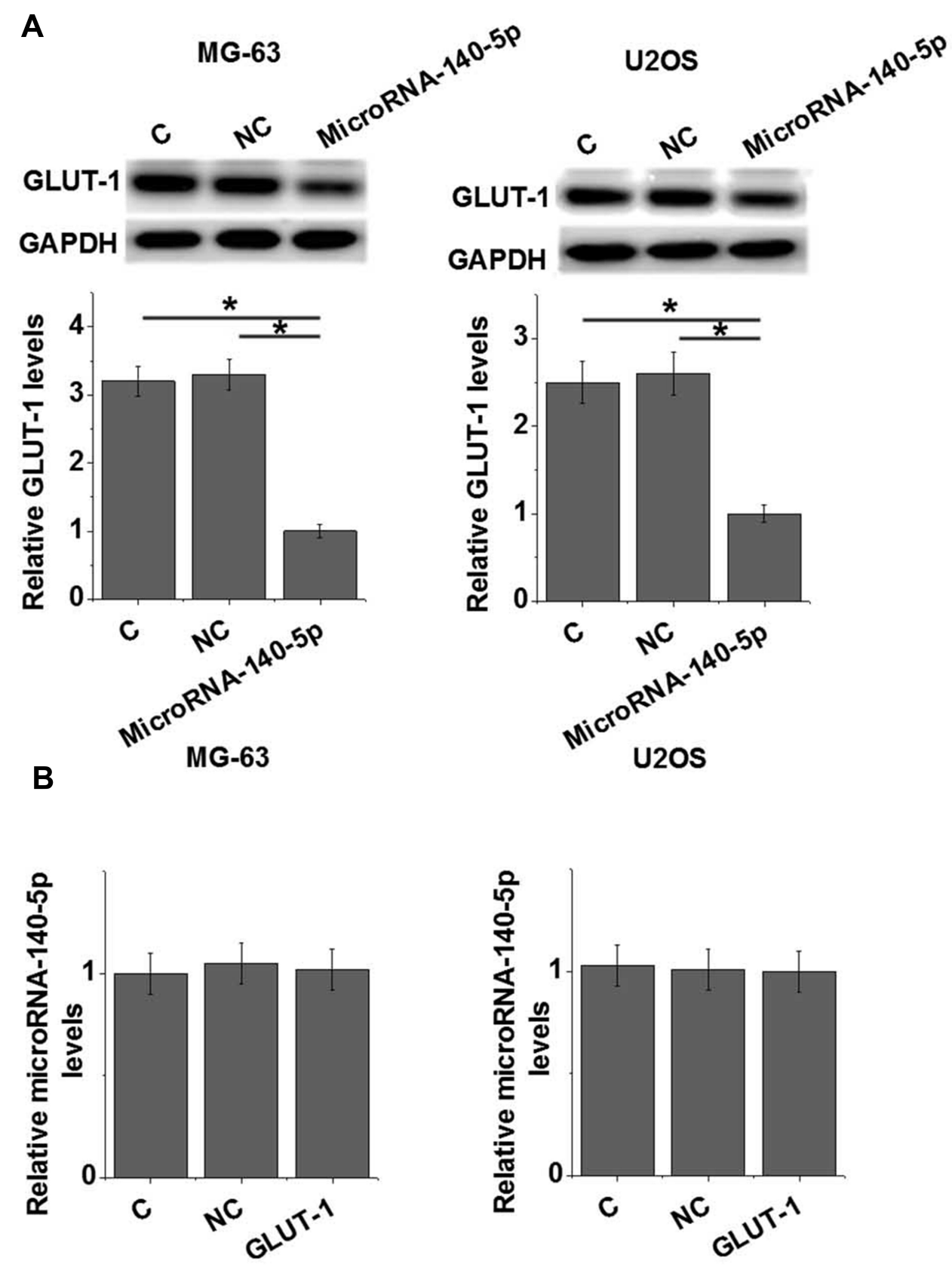

MG-63

U2OS

Figure 3 MicroRNA-I40-5p overexpression led to significantly upregulated GLUT-I. MicroRNA-I40-5p overexpression resulted in significantly down-regulated GLUT-I in cells of MG-63 and U2OS cell lines (A) $\left({ }^{*} \mathrm{p}<0.05\right)$, while GLUT-I overexpression showed no significant effect on microRNA-I40-5p expression in cells of MG-63 and U2OS cell lines (B).

microRNA-214 is observed in osteosarcoma patients comparing with healthy controls, which promotes tumor progression and leads to adverse prognosis. ${ }^{18}$ MicroRNA-140$5 p$ is a tumor suppression microRNA and is down-regulated in different types of cancers such as hepatocellular carcinoma $^{14}$ and colorectal cancer. ${ }^{15}$ In our study, we observed significantly lower plasma levels of microRNA$140-5 p$ in patients with osteosarcoma than those in healthy controls, indicating the potential role of microRNA-140-5p as a tumor suppression microRNA in osteosarcoma.

GLUT-1 is a central player in cancer biology that is usually upregulated during cancer development. ${ }^{9,19-21}$ Consistent with previous studies, ${ }^{9,19-21}$ our study also observed significantly upregulated plasma levels of GLUT-1 in osteosarcoma patients comparing with healthy controls. Inhibition of GLUT-1 leads to the inhibited 

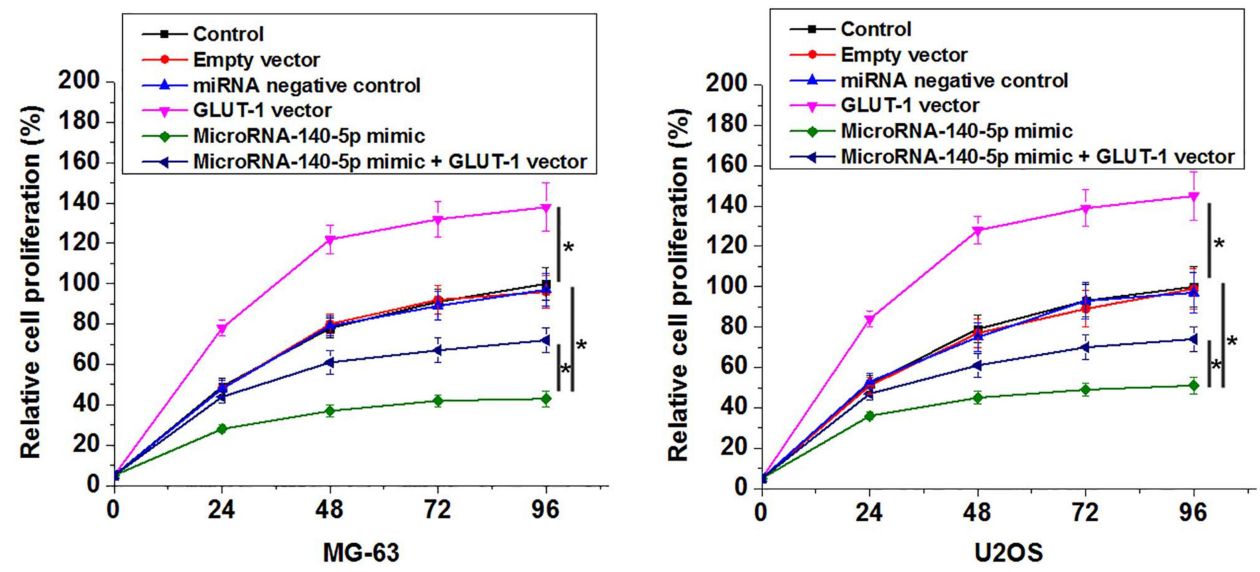

Figure 4 MicroRNA-I40-5p overexpression inhibited osteosarcoma cell proliferation by downregulating GLUT-I (*p<0.05).

growth of different types of cancers including osteosarcoma. In our study, we found microRNA-140-5p is likely to be an upstream activator of GLUT-1 in the growth of osteosarcoma due to the facts that: 1) microRNA-1405 pwas reversely correlated with GLUT-1 in osteosarcoma patients; 2) microRNA-140-5p overexpression led to significantly upregulated GLUT-1 expression, while GLUT-1 overexpression; on microRNA-140-5p expression; and 3) GLUT-1 overexpression significantly attenuated the inhibitory effects of microRNA-140-5p overexpression on osteosarcoma cell proliferation. Plasma levels of microRNA-140-5p showed no significant correlations with tumor metastasis. However, a significant correlation between plasma levels of microRNA-140-5p and tumor size was observed, indicating the specific involvement of microRNA-140-5p in tumor growth of osteosarcoma. Therefore, overexpression of microRNA-140-5p may serve as a potential therapeutic target for the treatment of osteosarcoma by inhibiting tumor growth through the downregulation of GLUT-1.

Interestingly, no significant correlation between plasma levels of microRNA-140-5pand GLUT-1 was observed in healthy controls. Therefore, the interaction between microRNA-140-5p and GLUT-1 is likely to be indirect or osteosarcoma-specific. However, the disease-related factors link microRNA-140-5p to GLUT-1 remains to be identified. This hypothesis is also supported by the observation that GLUT-1 overexpression only partially attenuated but not fully reversed the inhibitory effects of microRNA-140-5p overexpression on cancer cell proliferation. MicroRNA-140-5p may also interact with other pathways to participate the regulation of tumor growth in osteosarcoma.
In conclusion, microRNA-140-5p was significantly downregulated, while GLUT-1 was significantly upregulated in osteosarcoma patients comparing with healthy controls. MicroRNA-140-5p may inhibit the growth of osteosarcoma by downregulating the expression of GLUT-1. Proliferation and apoptosis of osteosarcoma are intricate biological processes which may involve in an army of molecules and factors. The present study just explored the function of MicroRNA-140-5p did on osteosarcoma proliferation/apoptosis of how it working. Our present research proposed a new targeted axial in treating of osteosarcoma.

\section{Disclosure}

The authors report no conflicts of interest in this work.

\section{References}

1. Isakoff MS, Bielack SS, Meltzer P, et al. Osteosarcoma: current treatment and a collaborative pathway to success. J Clin Oncol. 2015;33 (27):3029-3035. doi:10.1200/JCO.2014.59.4895

2. Andersen GB, Knudsen A, Hager H, Hansen LL, Tost J. miRNA profiling identifies deregulated miRNAs associated with osteosarcoma development and time to metastasis in two large cohorts. Mol Oncol. 2018;12:114-3110. doi:10.1002/1878-0261.12154

3. Ritter J, Bielack SS. Osteosarcoma. Annals of Oncology. 2010;21 (Suppl 7):vii320-vii325. doi:10.1093/annonc/mdq276

4. Ma H, He C, Cheng Y, et al. Localized co-delivery of doxorubicin, cisplatin, and methotrexate by thermosensitive hydrogels for enhanced osteosarcoma treatment. ACS Appl Mater Interfaces. 2015;7 (49):27040-27048. doi:10.1021/acsami.5b09112

5. Lamora A, Mullard M, Amiaud J, et al. Anticancer activity of halofuginone in a preclinical model of osteosarcoma: inhibition of tumor growth and lung metastases. Oncotarget. 2015;6(16):14413-14427. doi:10.18632/oncotarget.3891

6. Kang SW, Lee S, Lee EK. ROS and energy metabolism in cancer cells: alliance for fast growth. Arch Pharm Res. 2015;38(3):338-345. doi:10.1007/s12272-015-0550-6

7. Pollak M. Overcoming drug development bottlenecks with repurposing: repurposing biguanides to target energy metabolism for cancer treatment. Nat Med. 2014;20(6):591-593. doi:10.1038/nm.3596 
8. Olson AL, Pessin JE. Structure, function, and regulation of the mammalian facilitative glucose transporter gene family. Annu Rev Nutr. 1996;16(1):235-256. doi:10.1146/annurev.nu.16.070196.001315

9. Freemerman AJ, Johnson AR, Sacks GN, et al. Metabolic reprogramming of macrophages: glucose transporter (GLUT1)-mediated glucose metabolism drives a pro-inflammatory phenotype. J Biol Chem. 2014;13:522037.

10. Liu M, Gao J, Huang Q, et al. Downregulating microRNA-144 mediates a metabolic shift in lung cancer cells by regulating GLUT1 expression. Oncol Lett. 2016;11(6):3772-3776. doi:10.3892/ol.2016.4468

11. Pereira DM, Rodrigues PM, Borralho PM, et al. Delivering the promise of miRNA cancer therapeutics. Drug Discov Today. 2013;18(5-6):282-289. doi:10.1016/j.drudis.2012.10.002

12. Yang H, Fang F, Chang R, et al. MicroRNA-140-5p suppresses tumor growth and metastasis by targeting transforming growth factor $\beta$ receptor 1 and fibroblast growth factor 9 in hepatocellular carcinoma. Hepatology. 2013;58(1):205-217. doi:10.1002/hep.26315

13. Zhang W, Zou C, Pan L, et al. MicroRNA-140-5p inhibits the progression of colorectal cancer by targeting VEGFA. Cell Physiol Biochem. 2015;37(3):1123-1133. doi:10.1159/000430237

14. Jones KB, Salah Z, Del Mare S, et al. MicroRNA signatures associate with pathogenesis and progression of osteosarcoma. Cancer Res. 2012;72(7):1865-1877. doi:10.1158/0008-5472.CAN-11-2663

15. Duan Z, Choy E, Harmon D, et al. MicroRNA-199a-3p is down regulated in human osteosarcoma and regulates cell proliferation and migration. Mol Cancer Ther. 2011;10(8):1337-1345. doi:10.1158/1535-7163.MCT-11-0096
16. Wang Z, Cai H, Lin L, et al. Upregulated expression of microRNA214 is linked to tumor progression and adverse prognosis in pediatric osteosarcoma. Pediatr Blood Cancer. 2014;61(2):206-210. doi:10.1002/pbc. 24763

17. Yuan G, Zhao Y, Wu D, et al. miR-150 up-regulates GLUT1 and increases glycolysis in osteosarcoma cells. Asian Pac J Cancer Prev. 2017;18(4):1127-1131. doi:10.22034/APJCP.2017.18.4.1127

18. Jian F, Yuan F, Jiong M, et al. Silencing of glucose transporter protein-1 by RNA interference inhibits human osteosarcoma Mg63 cells growth in vivo. Technol Cancer Res Treat. 2015;14(2):243-248. doi:10.7785/tcrt.2012.500412

19. Bacci G, Bertoni F, Longhi A. Neoadjuvant chemotherapy for high-grade central osteosarcoma of the extremity. Histologic response to preoperative chemotherapy correlates with histologic subtype of the tumor. Cancer. 2003;97(12):3068-3075. doi:10.1002/cncr.11456

20. Luetke A, Meyers PA, Lewis I, et al. Osteosarcoma treatment where do we stand? A state of the art review. Cancer Treat Rev. 2014;40(4):523-532. doi:10.1016/j.ctrv.2013.11.006

21. Ma H, He C, Cheng Y, et al. PLK1shRNA and doxorubicin co-loaded thermosensitive PLGA-PEG-PLGA hydrogels for osteosarcoma treatment. Biomaterials. 2014;35(30):8723-8734. doi:10.1016/j. biomaterials.2014.06.045

\section{Publish your work in this journal}

OncoTargets and Therapy is an international, peer-reviewed, open access journal focusing on the pathological basis of all cancers, potential targets for therapy and treatment protocols employed to improve the management of cancer patients. The journal also focuses on the impact of management programs and new therapeutic agents and protocols on patient perspectives such as quality of life, adherence and satisfaction. The manuscript management system is completely online and includes a very quick and fair peer-review system, which is all easy to use. Visit http://www.dovepress.com/ testimonials.php to read real quotes from published authors 